\title{
ARTICLE
}

\section{Molecular characterization of sesame germplasms of West Bengal, India using RAPD markers}

\author{
Soumen Saha ${ }^{1,2}$, Tarak Nath Dhar ${ }^{1}$, Parthadeb Ghosh ${ }^{1}$, Tulsi Dey ${ }^{1,3^{*}}$ \\ ${ }^{1}$ Cytogenetics and Plant Biotechnology Research Unit, Department of Botany, University of Kalyani, Kalyani-741235, \\ Nadia, West Bengal, India \\ ${ }^{2}$ Cytogenetics and Plant Breeding Section, Department of Sericulture, Raiganj University, Raiganj-733134, Uttar \\ Dinajpur, West Bengal, India \\ ${ }^{3}$ Department of Botany, Kalyani Mahavidyalaya, Kalyani-741235, Nadia, West Bengal, India
}

\begin{abstract}
The aim of this research was to assess the genetic diversity of sesame (Sesamum indicum L.) and also to reveal the genetic relationships using the Random Amplified Polymorphic DNA (RAPD) markers. Fifteen sesame germplasms were collected from seven districts or four zones of West Bengal, India. A high genetic diversity was revealed by ten RAPD primers within and among the fifteen germplasms. The value of Jaccard's similarity coefficients among and within the fifteen germplasms ranged from 0.287 to 0.725 which indicated high degree of genetic variability. Cluster analysis using Unweighted Pair Group Method with Arithmetic Mean (UPGMA) grouped all the germplasms into three main clusters. Analysis of various genetic diversity indices strongly indicated high level of genetic diversity among the populations of four different regions. UPGMA analysis of four populations resulted into two groups and the results of Principal Coordinates Analysis (PCOA) depicted a clear distinction among the germplasms.

Acta Biol Szeged 63(1):15-24 (2019)
\end{abstract}

\section{KEY WORDS}

genetic diversity germplasm

molecular marker

Sesamum indicum

Random Amplified Polymorphic DNA

\section{ARTICLE INFORMATION}

Submitted

12 March 2019.

Accepted

3 July 2019

*Corresponding author

E-mail: deyugb2012@gmail.com

\section{Introduction}

Sesame (Sesamum indicum L., Pedaliaceae) is perhaps the oldest annual oilseed crop known to man. Based on its ancient history of cultivation, availability of diversity of forms of cultivated varieties and occurrence of the wild sesame (S. indicum var. malabaricum), India is considered to be the basic centre of origin of the crop (Brar et al. 1979). Sesame seeds are highly nutritive and are important source of oil (44-58\%) and protein (25\%) with lignan-type antioxidants such as sesamolin and sesamon (Bedigian et al. 1985). According to FAO (2016), about 10.57 million hectares were harvested worldwide in 2016, producing about 6.11 million tonnes. India leads the world in the sesame production and its contribution towards production quantity of sesame seeds in the world was $13.05 \%$ in the year 2016. Including India, other supreme sesame producers are China, Myanmar, Sudan, and Uganda covering about $75 \%$ of world production (Akbar et al. 2011). The yield of sesame in India was $4198 \mathrm{hg} / \mathrm{ha}$ compared to the world average of $5778 \mathrm{hg} / \mathrm{ha}$ in the year 2016 (FAO 2016). West Bengal is very rich in genetic diversity of sesame and is usually grown as a catch crop in the pre-kharif season (March-May to June-October). So far as West
Bengal is concerned, this state produces only 0.17 million tonnes of sesame seeds in the year 2010-2011, covering only about $19.1 \%$ with respect to all India production (Economic Review-Finance Department, Govt. of West Bengal, 2011-2012). Thus, the production of sesame seed in West Bengal is not so significant compared to the all India production and despite economic importance of sesame for the West Bengal as well as Indian economy, big fluctuations occur in production and yield. An extensive review of literature regarding the performance and production of sesame in India as well as in other countries reveals that many factors can be held responsible for low yield of such an important oilseed and the factors are absence of non-shattering cultivars suited for mechanical harvest, indeterminate growth, uneven ripening of capsules and biotic and abiotic stresses such as disease, pest drought, etc. (Abdellatef et al. 2008; Bhat et al. 1999), use of conventional varieties (Hamid et al. 2003), and lack of enhanced cultivars (Akbar et al. 2011).

Therefore, it is urgent to study the genetic diversity among sesame germplasms present in different zones of West Bengal and identification and catalogue of the highly diverse germplasms for the purpose of broadening the genetic base. The genetic diversity assessment in sesame has been carried out using both agro-morphological char- 
Saha et al.

Table 1. List of sesame germplasm from the state West Bengal, India used in this study.

\begin{tabular}{llllll}
\hline Germplasm number & Germplasm name & Zone of collection & Place of collection & Mean latitude & Mean longitude \\
\hline Acc-1 & VB-67 & North Zone & Murshidabad & $24^{\circ} 8^{\prime} 24^{\prime \prime} \mathrm{N}$ & $88^{\circ} 15^{\prime} 36^{\prime \prime} \mathrm{N}$ \\
Acc-2 & V-8-Sheera & North Zone & Murshidabad & $24^{\circ} 8^{\prime} 24^{\prime \prime} \mathrm{N}$ & $88^{\circ} 15^{\prime} 36^{\prime \prime} \mathrm{N}$ \\
Acc-3 & V-SWB-18 & North Zone & Murshidabad & $24^{\circ} 8^{\prime} 24^{\prime \prime} \mathrm{N}$ & $88^{\circ} 15^{\prime} 36^{\prime \prime} \mathrm{N}$ \\
Acc-4 & Seklar & North Zone & Murshidabad & $24^{\circ} 8^{\prime} 24^{\prime \prime} \mathrm{N}$ & $88^{\circ} 15^{\prime} 36^{\prime \prime} \mathrm{N}$ \\
Acc-5 & V-JTS-8 & North Zone & Murshidabad & $24^{\circ} 8^{\prime} 24^{\prime \prime} \mathrm{N}$ & $88^{\circ} 15^{\prime} 36^{\prime \prime} \mathrm{N}$ \\
Acc-6 & V-SWB-32-10-1 & North Zone & Murshidabad & $24^{\circ} 8^{\prime} 24^{\prime \prime} \mathrm{N}$ & $88^{\circ} 15^{\prime} 36^{\prime \prime} \mathrm{N}$ \\
Acc-7 & Rama & North Zone & Murshidabad & $24^{\circ} 8^{\prime} 24^{\prime \prime} \mathrm{N}$ & $88^{\circ} 15^{\prime} 36^{\prime \prime} \mathrm{N}$ \\
Acc-8 & East Zone & Burdwan & $23^{\circ} 14^{\prime} 24^{\prime \prime} \mathrm{N}$ & $87^{\circ} 51^{\prime} 36^{\prime \prime} \mathrm{N}$ \\
Acc-9 & Til-2 & East Zone & Hooghly & $22^{\circ} 53^{\prime} 24^{\prime \prime} \mathrm{N}$ & $88^{\circ} 24^{\prime} 00^{\prime \prime} \mathrm{N}$ \\
Acc-10 & Til-1 & East Zone & Howrah & $22^{\circ} 35^{\prime} 24^{\prime \prime} \mathrm{N}$ & $88^{\circ} 18^{\prime} 36^{\prime \prime} \mathrm{N}$ \\
Acc-11 & ST-1 & South 24 Parganas & $22^{\circ} 31^{\prime} 48^{\prime \prime} \mathrm{N}$ & $88^{\circ} 19^{\prime} 48^{\prime \prime} \mathrm{N}$ \\
Acc-12 & Savitri & South Zone & South 24 Parganas & $22^{\circ} 31^{\prime} 48^{\prime \prime} \mathrm{N}$ & $88^{\circ} 19^{\prime} 48^{\prime \prime} \mathrm{N}$ \\
Acc-13 & Tiloktama (B-67) & West Zone & East Midnapore & $22^{\circ} 18^{\prime} 00^{\prime \prime} \mathrm{N}$ & $87^{\circ} 54^{\prime} 36^{\prime \prime} \mathrm{N}$ \\
Acc-14 & GT-2 & West Zone & East Midnapore & $22^{\circ} 18^{\prime} 00^{\prime \prime} \mathrm{N}$ & $87^{\circ} 54^{\prime} 36^{\prime \prime} \mathrm{N}$ \\
Acc-15 & GT-3 & West Zone & West Midnapore & $22^{\circ} 25^{\prime} 48^{\prime \prime} \mathrm{N}$ & $87^{\circ} 19^{\prime} 48^{\prime \prime} \mathrm{N}$ \\
\hline
\end{tabular}

acters (Bedigian 2010; Ercan et al. 2002; Furat et al. 2010; Pham et al. 2010) and molecular markers such as isozymes (Isshiki et al. 1997), Randomly Amplified Polymorphic DNA (RAPD; Akbar et al. 2011; Bhat et al. 1999; Ercan et al. 2004; Pham et al. 2009; Salazar et al. 2006), Inter Simple Sequence Repeat (ISSR; Kim et al. 2002; Kumar et al. 2012; Woldesenbet et al. 2015), Amplified Fragment Length Polymorphism (AFLP; Uzun et al. 2003), Simple Sequence Repeat (SSR; Dixit et al. 2005; Zhang et al. 2012; Pandey et al. 1015) and Sequence-related Amplified Polymorphism (SRAP; Ali et al. 2017). Among the various available molecular markers, we have selected RAPD for the assessment of genetic diversity (Williams et al. 1990) owing to its simplicity, speed and low cost. Being a fast

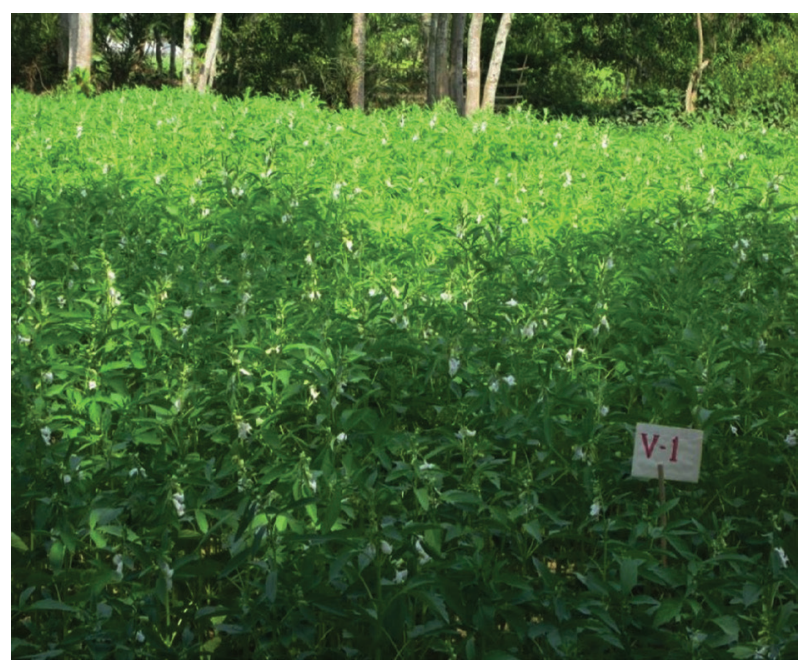

Figure 1. Sesame plants growing in the experimental plant garden. and sensitive method, RAPD can be quickly and efficiently applied to identify polymorphisms (Doldi et al. 1997; Ko et al. 1998). Moreover, the resolving power of this tool is numerous folds superior than morphological or isozyme markers and is much simpler and technically less demanding than RFLP and other new generation markers. RAPD markers have successfully established their grandness for diversity analysis in many cultivated and wild plants such as Morus alba (Orhan et al. 2007), Vigna unguiculata (Malviya et al. 2012), Linum usitatissimum (Kumari et al. 2017) and also in S. indicum (Bhat et al. 1999; Ercan et al. 2004; Quenum and Yan 2017).

This communication sets out to enumerate the results of our efforts pertaining to the evaluation of genetic variation among fifteen germplasms collected from seven districts of West Bengal and determination of relationship between genetic diversity of sesame population and their geographical distribution within four zones of the state.

\section{Materials and methods}

\section{Plant materials}

On the basis of diversity in vegetative and reproductive characters, the 15 indigenous germplasms (accessions) of West Bengal were used in this study (Table 1) and were grown in the experimental garden (Fig. 1) of Department of Botany, University of Kalyani, West Bengal, India which is located at $22^{\circ} 57^{\prime} \mathrm{N}$ latitude, $88^{\circ} 22^{\prime}$ E longitude with an average altitude of $9.75 \mathrm{~m}$ above mean see level. Physicochemical properties of soil and meteorological information are provided in the Supplementary Table $1 \mathrm{a}$ and $\mathrm{b}$. 


\section{DNA extraction}

Fresh tender leaves were collected from ten plants of each germplasm and quickly frozen with liquid nitrogen. Total genomic DNA was extracted based on hexadecyltrimethylammonium bromide (CTAB) procedure (Murray et al. 1980) with minor modifications. The DNA concentration was quantified by spectrophotometry (Cecil, Germany). Thus, the estimated DNA concentrations were rechecked by ethidium bromide staining of the gels after electrophoresis in $0.8 \%$ agarose gel.

\section{RAPD analysis}

A set of 25 randomly selected oligonucleotide primers (Bangalore Genei, India) were used for RAPD assay. Each $50 \mu$ l RAPD polymerase chain reaction (PCR) mixture included 50 ng genomic DNA (template), $10 \mathrm{mM} \mathrm{dNTPs,}$ $5 \mu \mathrm{l}$ of $10 \mathrm{X}$ Taq polymerase buffer, $1.0 \mathrm{mM} \mathrm{MgCl}_{2}, 3 \mathrm{U}$ of Taq DNA polymerase enzyme and 400 ng RAPD primers. The final volume of $50 \mu \mathrm{l}$ was made up with PCR grade water (Genie, Bangalore, India). The reaction mixture was subjected to amplification using Perkin Elmer GeneAmp 2400 PCR system according to the following program: 5 min at $94{ }^{\circ} \mathrm{C}$ for initial denaturation, followed by 45 cycles of $1 \mathrm{~min}$ denaturation at $94^{\circ} \mathrm{C}, 1 \mathrm{~min}$ annealing at $38^{\circ} \mathrm{C}$, and 2 min extension at $72^{\circ} \mathrm{C}$. The reaction mixture was further incubated at $72^{\circ} \mathrm{C}$ for $5 \mathrm{~min}$. Amplification products were separated in $1.5 \%$ agarose gel mixed in $1 \mathrm{X}$ TAE buffer at $70 \mathrm{~V}$ for $1.3 \mathrm{~h}$ and were visualised by staining with ethidium bromide. DNA ladder $(2 \mathrm{~kb})$ with fragment size 100 to $2000 \mathrm{bp}$ was used as a molecular size marker. The gel was observed under ultraviolet light on a transilluminator and photographed using Gel Documentation System 1000 (Bio-Rad).

\section{Data analysis}

Since the RAPD markers are dominant, genetic data analysis was carried out on the assumption that each band represented the phenotype at a single biallelic locus. Amplification with each arbitrary primer was repeated three times and consistent bands were selected for data generation. The presence and absence of bands were scored as the presence (1) or absence (0), respectively. DNA fragment intensity was not taken into consideration and the bands with the same mobility were considered to be the same bands. Only main DNA fragments constantly amplified were scored and weak bands were not utilised for analysis. By comparing the banding patterns of genotypes (germplasms) for a specific primer, genotype-specific bands were identified. The binary data so generated was used to estimate the levels of polymorphism by dividing the polymorphic bands by the total number of scored bands. To analyze the suitability of RAPD markers for evaluating the genetic profiles of sesame performance of the markers was measured using three parameters: (i) polymorphic information content (PIC), (ii) marker index (MI) and (iii) resolving power (RP). The PIC value for each locus was calculated using the formula: PIC $=2 \mathrm{fi}(1-\mathrm{fi})$, where fi is the frequency of the amplified fragments (band present) and 1 - fi is the frequency of non-amplified fragments (band absent) (Roldán-Ruiz et al. 2000). The frequency was calculated as the ratio between the number of amplified bands at each locus and the total number of accessions (excluding missing data). The PIC of each primer was calculated using the average PIC value from all loci of each primer. MI was calculated applying the formula: $\mathrm{MI}=\mathrm{EMR} \times \mathrm{PIC}$, where EMR (effective multiplex ratio) is the product of the fraction of polymorphic loci and the number of polymorphic loci for an individual assay (Varshney et al. 2007). RP of each primer was calculated according to Prevost and Wilkinson (1999): $\mathrm{RP}=\Sigma \mathrm{Ib}$, where $\mathrm{Ib}$ represents the informative fragments. The Ib can be represented on a scale of 0 to 1 by the following formula: $\mathrm{Ib}=1-[2 \times(0.5-\mathrm{p})]$, where $\mathrm{p}$ is the proportion of accessions containing the band. The genotype and allelic frequency data were used to compute the genetic diversity indices, that is, (i) percentage of polymorphic loci [P\% = (polymorphic loci/total loci) $\times 100]$, (ii) observed (na) and effective number of alleles (ne), where ne is the number of equally frequent alleles that would be necessary to achieve the same degree of genetic diversity produced by na, (iii) Shannon's Information Index (I) (Shannon et al. 1949) calculated from $I=(\Sigma$ pi $\log$ pi), where pi is the frequency of RAPD fragments amplified in the accessions and $\mathrm{L}$ is the total number of fragments and (iv) Nei's genetic diversity (h) (Nei 1973) derived from $h=1-\Sigma$ pi2, where pi is the frequency of the $\mathrm{i}^{\text {th }}$ allele at the locus, were calculated with the aid of the POPGENE program version 1.31 (Yeh et al. 1999). For each locus, the Nei's index produces values between 0 and 0.5 , while the Shannon index varies from 0 to 0.73 according to a natural log scale (Lowe et al. 2004).

The binary data matrix was used to calculate Jaccard's similarity coefficient (Jaccard 1908) between pairs of accessions using the Simqual module of NTsys-PC (Numerical Taxonomy System, version 2.1) (Rohlf 1993). These distance coefficients were used to construct dendrogram using the Unweighted Pair Group Method with Arithmetic Mean (UPGMA) employing the Sequential Agglomerative Hierarchical and Nested (SAHN) algorithm for determining the genetic diversity and relationships among the accessions. In order to highlight the resolving power of the ordination, Principal Coordinates Analysis (PCoA) was performed using the EIGEN and PROJ modules of NTSYS Pc. 


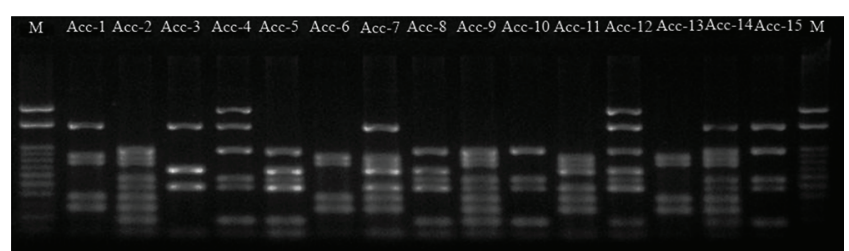

Figure 2. RAPD profile of the 15 accessions (Acc 1-15) of Sesamum indicum $\mathrm{L}$. generated by primer OTD-01.

\section{Results}

To assess the genetic diversity and relationship among 15 germplasms, a total of 25 RAPD primers were screened, out of which ten primers revealed reproducible polymorphic patterns (Fig. 2) and were used for further study. Two main aspects of genetic diversity-marker informativeness (polymorphic and overall efficiency of informative fragment detection) and marker performance (overall efficacy of a primer set used in determining polymorphism level, genetic diversity, and discriminatory power) were estimated (Table 2).

\section{Marker informativeness}

Marker informativeness of ten RAPD primers was evaluated using different parameters (Table 2). A total of 116 clear, reproducible and scorable RAPD fragments ranging from 100 to $2000 \mathrm{bp}$ were generated among all germplasms. Out of 116 scorable RAPD bands, 110 were polymorphic and 6 were monomorphic. Each primer was tried thrice, and the results were reproducible. In general, 10 to 12 amplified fragments were scored depending upon the primers. The number of polymorphic bands per primers ranged from nine (OTD4) to twelve (OTD1, OTD2, OTD5) with an average of eleven (Table
2). Selections of polymorphic alleles were carried out in a careful manner and only the clear, reproducible and polymorphic bands were scored and used for statistical analysis. The percentage of polymorphic bands ranged from 90\% (OTD4, OTD6, and OTD7) to 100\% (OTD1, OTD2, OTD3, and OTD5), with a high average value of $94.42 \%$ (Table 2). The ranges of frequencies of polymorphic fragments for a given primer across for all germplasms were 0.066 to 1 with an average of 0.55 . A large proportion (55.17) had frequencies in the range 0.5 to 0.6 (Fig. 3).

\section{Marker performance}

Information on the genetic profile of each germplasm was used to assess the marker performance by evaluating the PIC, EMR, MI and RP (Table 2). The range of PIC for 110 polymorphic fragments obtained by using ten RAPD primers was 0.37 to 0.44 with an average of 0.40. Eighty-three of polymorphic fragments were highly informative (PIC $\geq 0.44$ ), six had lower level of PIC $(\geq 0.1)$ and the remaining twenty seven showed moderate values $(\geq 0.1$ to $<0.44)$ (Fig. 4). The highest PIC value (0.44) was observed for primer OTD1 and the lowest PIC value (0.37) was observed for OTD9 (Table 2).

The highest EMR (12) was observed for the primer OTD1, OTD2 and OTD5 and the mean EMR per primer was 11 (Table 2). To determine the overall utility of the maker system, the marker index was calculated for each RAPD primer. The marker index for the ten primers ranged from 1.91 (OTD4) to 2.88 (OTD2 and OTD5) with an average 2.416 (Table 2). The resolving power of RAPD primers is a feature that indicates a discriminatory potential of the primer ranged from 1.03 (OTD8) to 1.14 (OTD2, OTD5), averaging 1.095 (Table 2). No significant correlation was found between

Table 2. Polymorphism and marker attributes of RAPD primers.

\begin{tabular}{|c|c|c|c|c|c|c|c|c|c|}
\hline \multirow{2}{*}{ Primer name } & \multirow{2}{*}{ Sequence $\left(5^{\prime}-3^{\prime}\right)$} & \multicolumn{3}{|c|}{ Number of fragments } & \multirow{2}{*}{$\begin{array}{l}\text { \% Polymor- } \\
\text { phism }\end{array}$} & \multirow{2}{*}{ PIC } & \multirow{2}{*}{ EMR } & \multirow{2}{*}{$\begin{array}{l}\text { Marker } \\
\text { index }\end{array}$} & \multirow{2}{*}{$\begin{array}{l}\text { Resolving } \\
\text { power }\end{array}$} \\
\hline & & Total & Monomorphic & Polymorphic & & & & & \\
\hline OTD-01 & TTGGCGGCCT & 12 & 0 & 12 & 100 & 0.44 & 12 & 2.87 & 1.09 \\
\hline OTD-02 & ACCTCGCCAC & 12 & 0 & 12 & 100 & 0.42 & 12 & 2.88 & 1.14 \\
\hline OTD-03 & GAGGTCCACA & 11 & 0 & 11 & 100 & 0.38 & 11 & 2.25 & 1.08 \\
\hline OTD-04 & TGCCGAGCTG & 10 & 1 & 9 & 90 & 0.39 & 9 & 1.91 & 1.09 \\
\hline OTD-05 & AGTCAGCCAC & 12 & 0 & 12 & 100 & 0.42 & 12 & 2.88 & 1.14 \\
\hline OTD-06 & GGGTAACGCC & 12 & 1 & 11 & 90 & 0.38 & 11 & 2.27 & 1.09 \\
\hline OTD-07 & AGGTGACCGT & 12 & 1 & 11 & 90 & 0.41 & 11 & 2.53 & 1.12 \\
\hline OTD-08 & CTGGGCAACT & 11 & 1 & 10 & 90.9 & 0.41 & 10 & 2.11 & 1.03 \\
\hline OTD-09 & AGGCGGGAAC & 12 & 1 & 11 & 91.66 & 0.37 & 11 & 2.21 & 1.09 \\
\hline OTD-10 & AGGTCTTGGG & 12 & 1 & 11 & 91.66 & 0.38 & 11 & 2.25 & 1.08 \\
\hline Total & - & 116 & 6 & 110 & - & - & - & - & - \\
\hline Average & - & 11.6 & 0.6 & 11 & 94.42 & 0.4 & 11 & 2.416 & 1.095 \\
\hline
\end{tabular}




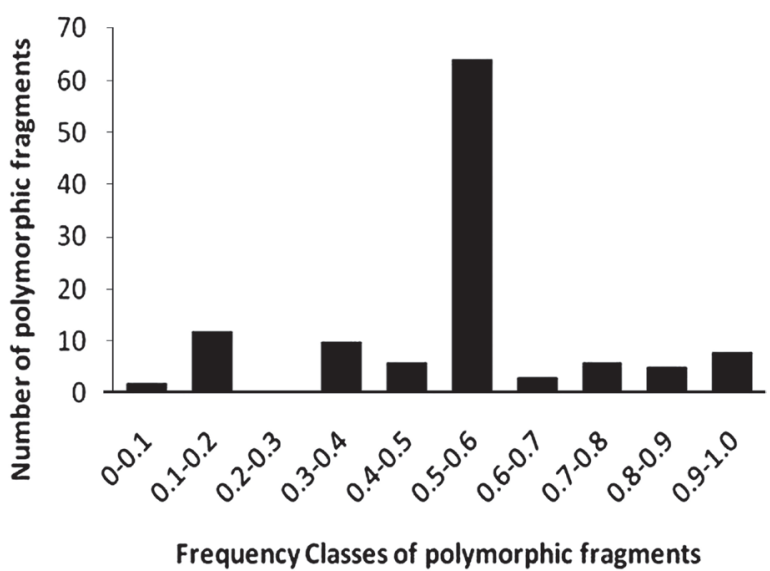

Figure 3. Frequency distribution of polymorphic RAPD fragment amplified in 15 sesame germplasms.

the number of neither fingerprint nor lines with exclusive finger print with PIC, resolving power and marker index.

\section{Genetic diversity at zone level}

Using the RAPD amplification result, the genetic diversity of the four regions of West Bengal was analyzed (Table 3 ). The range of mean number of alleles $\left(\mathrm{n}_{\mathrm{a}}\right)$ based on RAPD analysis was 1.55 to 1.92 and the effective number of alleles $\left(\mathrm{n}_{\mathrm{e}}\right)$ was 1.53 to 1.73 . The Shannon's information index $(I)$ was 0.38 to 0.57 and the Nei's gene diversity index $(h)$ was 0.27 to 0.39 .

Analysis of RAPD data showed that north zone, west zone and east zone displayed more variation and the respective coefficients were $92.24,77.59$, and $67.24 \%$. According to the number of polymorphic loci, the ranking of the regions was north zone > west zone > east zone > south zone. Table 3 shows that a general consistency is retained in different indexes of genetic diversity using RAPD marker and the polymorphic locus percentages was about more than $90 \%$. These findings strongly indicated the high genetic variation among the sesame germplasms of four different regions and the RAPD marker approach

Table 3. Estimates of genetic diversity within four population/zones using RAPD markers.

\begin{tabular}{llllll}
\hline Index & North Zone & East Zone & South Zone & West Zone & All \\
\hline $\mathrm{n}_{\mathrm{a}}$ & 1.92 & 1.67 & 1.55 & 1.77 & 1.94 \\
$\mathrm{n}_{\mathrm{e}}$ & 1.73 & 1.53 & 1.55 & 1.62 & 1.75 \\
$\mathrm{~h}$ & 0.39 & 0.29 & 0.27 & 0.34 & 0.40 \\
$\mathrm{I}$ & 0.57 & 0.42 & 0.38 & 0.49 & 0.57 \\
$\mathrm{P} \%$ & 92.24 & 67.24 & 55.17 & 77.59 & 94.83 \\
\hline
\end{tabular}

na $=$ average number of alleles; ne = effective number of alleles; $h=$ heterozygosity; I = Shannon's index; $\mathrm{P}=$ percentage of polymorphic loci

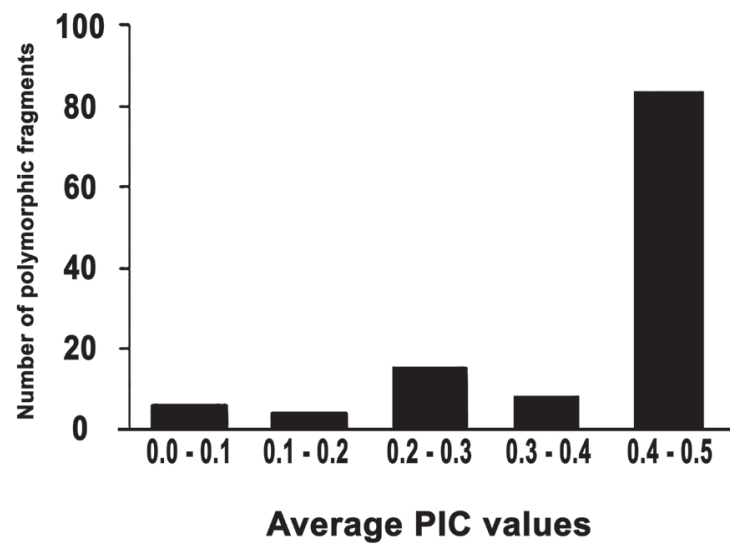

Figure 4. Average PIC values for polymorphic fragments generated by RAPD primers in 15 sesame germplasms.

was effective for the detection. For the level of gene flow $(\mathrm{Nm})$, the number of migrating individuals among the population per generation was estimated to be 2.30 using RAPD marker which indicated that gene exchange between populations was rather high.

The genetic similarities were calculated following the Jaccard's coefficient (Jaccard 1908) method using the RAPD data. The similarity index ranged from 0.188 to 0.603 with an average of 0.276 (Table 4) indicating a close genetic relationship among the Sesamum germplasm of four different regions. The calculated similarity coefficient was utilized to prepare a tree for cluster analysis using UPGMA method (Fig. 5). The cluster analysis generated a sister group consisting of populations of east zone, west zone, and south zone. Moreover, results indicated that populations of east zone and west zone were found to be more similar (60\%), while populations of north zone was outlier. The populations of north zone were separated from the other populations showing their maximum genetic dissimilarity.

\section{Genetic diversity-phylogenetic relationship and PCOA analysis}

The genetic similarities were calculated using the Jaccard's coefficient (Jaccard 1908) method for all the 15 germplasms of $S$. indicum according to RAPD data analysis. Based on

Table 4. Similarity matrix based on Jaccard's coefficient revealed by RAPD marker within four populations/zones.

\begin{tabular}{lllll}
\hline Index & North Zone & East Zone & South Zone & West Zone \\
\hline North Zone & 1.000 & & & \\
East Zone & 0.246 & 1.000 & & \\
South Zone & 0.188 & 0.308 & 1.000 & \\
West Zone & 0.262 & 0.603 & 0.310 & 1.000 \\
\hline
\end{tabular}



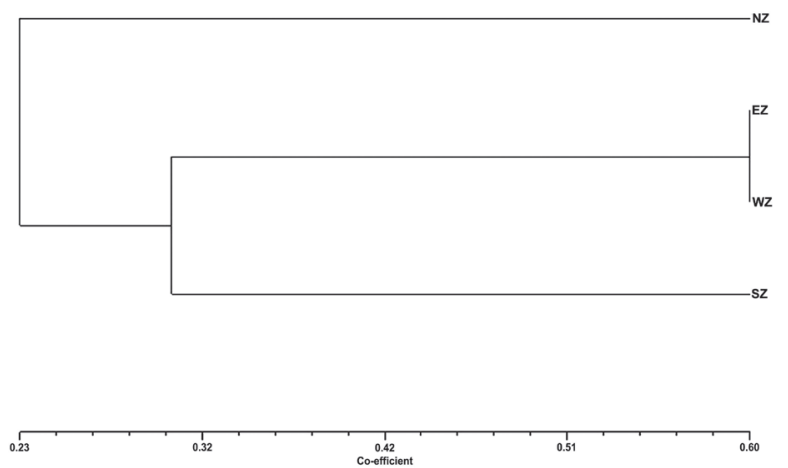

Figure 5. UPGMA dendrogram within four populations (zones) based on JACCARD's similarity coefficient calculated from RAPD data set.

the RAPD markers, the similarity index value ranged from 0.287 to 0.725 (Table 5) indicating a close genetic relationship within the varieties. The calculated similarity coefficients were utilized to construct a dendrogram using UPGMA. A dendrogram was prepared using UPGMA clustering algorithm based on RAPD data and fifteen varieties were grouped into three main cluster; cluster (I) containing three germplasms, cluster (II) containing a total of six germplasms and cluster (III) containing six germplasms (Fig. 6). By providing spatial representation of relative genetic distances among individuals, the PCoA analysis was performed to determine the consistency of the differentiation among the germplasms defined by the cluster analysis. The PCoA indicated that the effect of individual amplification products on the overall variation observed was lesser, hence a total of ten RAPD products were required to explain $94.83 \%$ of the variation among the fifteen sesame germplasms. The analysis indicated that, the first two principle coordinates accounted for $54.46 \%$ of the total variation, while the remaining coordinates individually were less than $5.00 \%$ each. Therefore, the biplot of only the first two coordinates are presented in Figure 7 and similar result was observed like that of three-dimensional representations (Fig. 8). The results from PCoA plot of the 15 sesame accessions reveal a clear distinction among the germplasms. The PCoA plot analysis was in congruence with the UPGMA cluster analysis.

\section{Discussion}

Accurate identification of germplasms of crop species and varieties by means of DNA fingerprints is important particularly when new crop varieties are to be released, different accessions of wild species are to be characterized and purity of germplasms is to be determined. RAPD markers were utilized in this study to evaluate the level of genetic variation among the 15 germplasms of $S$. indicum L. collected from different districts of West Bengal, India. The RAPD technique has been chosen as it does not require any previous knowledge on DNA sequence of this species, is an inexpensive and easy to use for evaluating the degree of genetic diversity in sesame and many other plant species (Akbar et al. 2011; Bhat et al. 1999; Ercan et al. 2004; Salazar et al. 2006; Sangwan et al. 2001; Sharma et al. 2009; Vieira et al. 2003; Singh et al. 2017; Dar et al. 2017).

Ten RAPD primers detected sufficient genetic variation within fifteen sesame germplasms to allow for complete

Table 5. Genetic similarity coefficients among fifteen sesame germplasm realized from RAPD markers.

\begin{tabular}{|c|c|c|c|c|c|c|c|c|c|c|c|c|c|c|c|}
\hline Correlation & Acc-1 & Acc-2 & Acc-3 & Acc-4 & Acc-5 & Acc-6 & Acc-7 & Acc-8 & Acc-9 & Acc-10 & Acc-11 & Acc-12 & Acc-13 & Acc-14 & Acc-15 \\
\hline Acc-1 & 1.000 & & & & & & & & & & & & & & \\
\hline Acc-2 & 0.347 & 1.000 & & & & & & & & & & & & & \\
\hline Acc-3 & 0.322 & 0.379 & 1.000 & & & & & & & & & & & & \\
\hline Acc-4 & 0.378 & 0.388 & 0.352 & 1.000 & & & & & & & & & & & \\
\hline Acc-5 & 0.471 & 0.473 & 0.425 & 0.330 & 1.000 & & & & & & & & & & \\
\hline Acc- 6 & 0.526 & 0.376 & 0.353 & 0.379 & 0.287 & 1.000 & & & & & & & & & \\
\hline Acc-7 & 0.355 & 0.725 & 0.506 & 0.327 & 0.440 & 0.419 & 1.000 & & & & & & & & \\
\hline Acc-8 & 0.444 & 0.495 & 0.593 & 0.523 & 0.452 & 0.482 & 0.402 & 1.000 & & & & & & & \\
\hline Acc-9 & 0.442 & 0.528 & 0.309 & 0.506 & 0.483 & 0.304 & 0.444 & 0.381 & 1.000 & & & & & & \\
\hline Acc-10 & 0.481 & 0.344 & 0.487 & 0.458 & 0.544 & 0.345 & 0.309 & 0.494 & 0.391 & 1.000 & & & & & \\
\hline Acc-11 & 0.512 & 0.478 & 0.382 & 0.422 & 0.483 & 0.538 & 0.494 & 0.441 & 0.422 & 0.287 & 1.000 & & & & \\
\hline Acc-12 & 0.438 & 0.538 & 0.396 & 0.404 & 0.446 & 0.459 & 0.576 & 0.533 & 0.361 & 0.404 & 0.347 & 1.000 & & & \\
\hline Acc-13 & 0.494 & 0.398 & 0.393 & 0.371 & 0.382 & 0.481 & 0.333 & 0.580 & 0.488 & 0.353 & 0.402 & 0.340 & 1.000 & & \\
\hline Acc-14 & 0.506 & 0.571 & 0.398 & 0.484 & 0.495 & 0.351 & 0.522 & 0.500 & 0.688 & 0.376 & 0.484 & 0.418 & 0.372 & 1.000 & \\
\hline Acc-15 & 0.364 & 0.517 & 0.506 & 0.425 & 0.543 & 0.506 & 0.448 & 0.477 & 0.333 & 0.539 & 0.494 & 0.422 & 0.341 & 0.351 & 1.000 \\
\hline
\end{tabular}




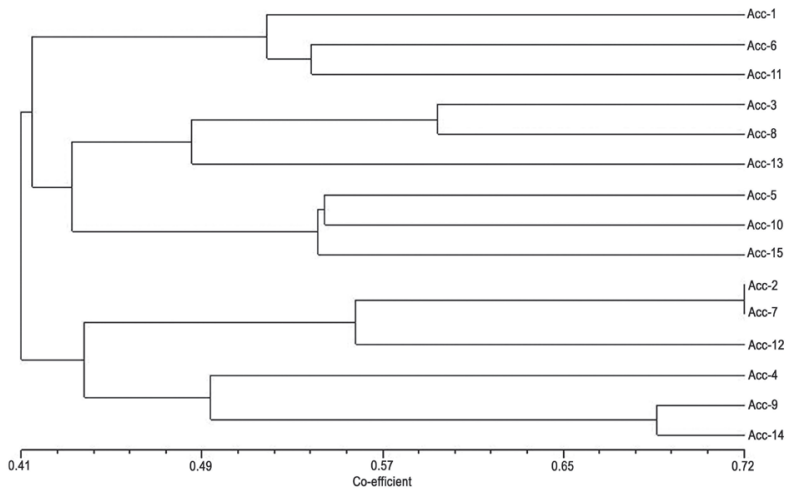

Figure 6. JACCARD's similarity dendrogram of the 15 germplasms (Acc1-Acc15) generated by UPGMA based on RAPD marker system.

differentiation. According to Li and Midmore (1999) when the variation between genotype is high the use of few primers will be sufficient. For instance, Ercan et al. (2004) identified thirty-eight accessions only by using seven primers while twenty sesame genotypes were determined with ten primers by Akbar et al. (2011). Similarly, Millan et al. (1996) reported a high level of genetic diversity among rose genotypes using nearly ten RAPD primers. Schontz and Rether (1999) identified 37 lines of Foxtail millet employing just 4 RAPD primers.

A high level of genetic diversity was observed among the 15 germplasms of sesame. Although, sesame is generally followed by self-pollination, but cross pollination has been reported between 5 and 60\% in this species

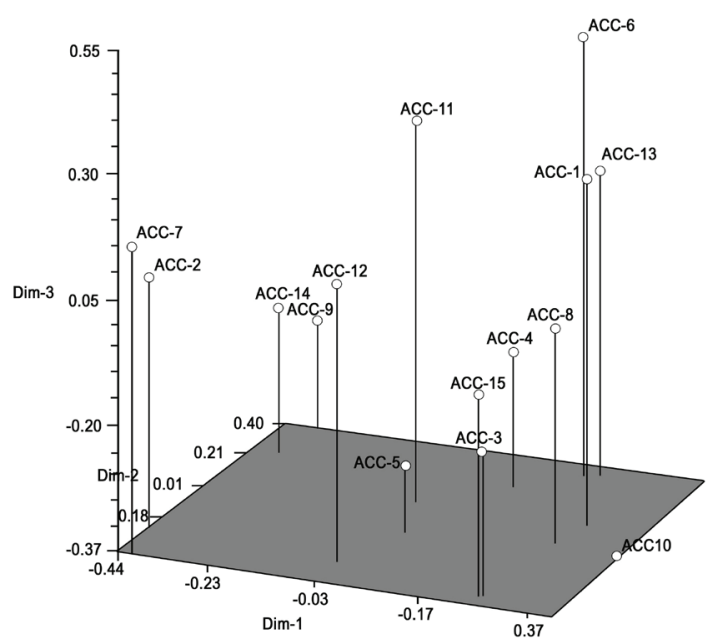

Figure 8. Three-dimensional plot obtained from Principal Coordinates Analysis (PCOA) of fifteen sesame germplasms using RAPD markers.

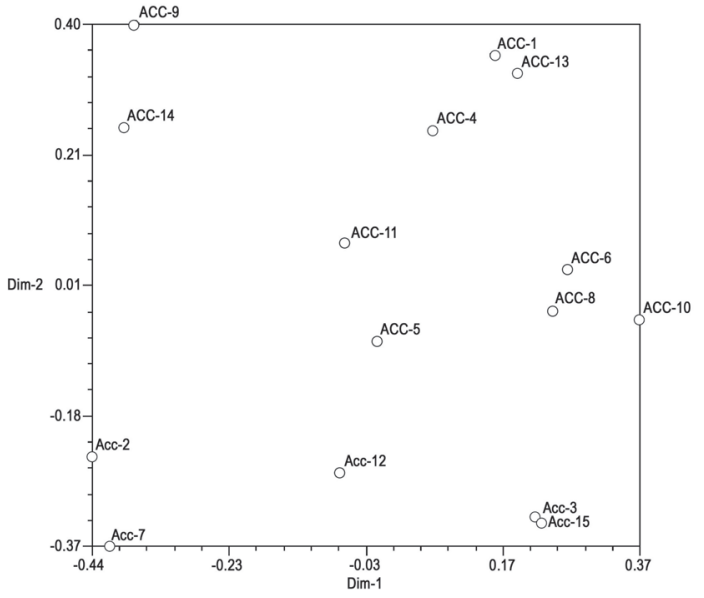

Figure 7. Two-dimensional plot obtained from Principal Coordinates Analysis (PCOA) of fifteen sesame germplasms using RAPD markers.

(Ashri 1989; Brar et al. 1979; Joshi 1961; Mazanni 1983; Yermanos 1980). Approximately 10 to $20 \%$ of the genetic diversity among the population is since out crossing could explicate the high genetic variability noticed in the present study. The present results are in conformity with the results of earlier workers based on RAPD and morpho-agronomic traits which have reported high genetic diversity in sesame germplasms (Akbar et al. 2011; Ashri 1998; Bhat et al. 1999; Ercan et al. 2004; Pham et al. 2009; Salazar et al. 2006).

Applying different methods would provide different results on the level of genetic diversity. Isshiki and Umezki (1997), reported little variation among 68 accessions of cultivated sesame employing isozymes. Laurentin and Karvilsky (2006) applied AFLP to clarify genetic relationship among 32 sesame accessions from the Venezuelan germplasms collections and reported a very low genetic relationship and diversity (0.14 to 0.21 ). ISSR polymorphism was used to determine the genetic relationship among 75 sesame accessions of Korea and other countries showed a low level of polymorphism with this particular marker and genetic distances ranged from 0 to 0.255 (Kim et al. 2002). However, it was shown that their method had low resolution.

In contrast, a very high level of genetic diversity among sesame accessions by means of RAPD molecular markers has been reported by Bhat et al. (1999), Ercan et al. (2004), Akbar et al. (2011), Dar et al. (2017) and Quenum and Yan (2017). The present study detected a high level of polymorphism for sesame between the different geographical areas of West Bengal. In the present study, a high level of polymorphism (94.42\%) obtained is comparable to the $86.75 \%$ polymorphism noticed in a study of genetic diversity in Indian and exotic sesame germplasms by 
Bhat et al. (1999) and also analogous to $82.99 \%$ observed in a study of genetic diversity of sesame of Vietnam and Cambodia (Pham et al. 2009). Salazar et al. (2006) also observed $100 \%$ of polymorphism in an analysis of genetic diversity of sesame of Venezuela. Ercan et al. (2004) also reported 78\% polymorphism in an analysis of genetic diversity in Turkish sesame. Although, a considerable level of genetic diversity was noticed among diverse sesame germplasms collected from various geographical regions of West Bengal, it was found that some accessions situated geographically far apart were grouped together in the same cluster such as Acc-1 and Acc-6 (from north zone) and Acc-11 (from south zone) grouped together in cluster I (Fig. 6). Similarly, in the cluster II germplasms of north zone (Acc-3 and Acc-5), east Zone (Acc-8 and Acc-10) and west zone (Acc-13 and Acc-15) were clustered together. Furthermore, cluster III germplasms collected from different regions of West Bengal appeared in the identical group such as north zone (Acc-2, Acc-4 and Acc-7), south zone (Acc-12), east zone (Acc-9) and west zone (Acc-14). This could be an outcome of large movement of West Bengal farmers to different regions of the state carrying sesame seeds for cultivation into their new geographical locations. According to Bhat et al. (1999), the cultivation practices and consumer preferences in respect to seed colour and seed texture and other quality attributes differ widely with the of cultivation. Stankiewicz et al. (2001) pointed out that human factor could be responsible for lack of association between genetic and geographical detachment in some cases. Germplasms collected from the same zone were found to have a close genetic relationship for example cluster I included germplasms Acc-1 and Acc- 6 from North Zone and Acc-8, Acc-10 from East Zone in cluster II. Interestingly, all the three clusters included germplasms collected from north zone (Murshidabad district) which may be a consequence of largely substantial movement of farmers of Murshidabad district to different regions of West Bengal for collection of diverse germplasms of sesame for cultivation.

Using the RAPD results, attempts have been made to analyse the genetic diversity from the four different geographical zones of West Bengal. From the result it can be summarized that least gene diversity was among the germplasms collected from the south zone or South 24 Parganas district and the highest among germplasms of north zone or Murshidabad district. The same order of genetic heterogeneity was discerned to Shannon's information index (north zone > west zone > east zone > south zone) and the level of gene flow was 2.30. From the standpoint of population genetics, a value of gene flow $(\mathrm{Nm})<1$ (less than one migrant/generation into a population) or equivalently a value of genetic differentiation (Gst) $>0.25$ is generally regarded as the threshold quantity beyond which significant population differentiation occurs (Slatin 1987). The high flow among the population detected in this study points towards the possibility of instances of single isolated populations possessing unique germplasms also found in other populations and which is in conformity with the studies of Naik et al. (2010).

Little studies have been carried out about the discriminatory power of RAPD primers in sesame (Salazar et al. 2006). But similar studies have been done in other crops such as Glycin max (Powell et al. 1996), Hordeum vulgare (Russell et al. 1997), Jatropha curcus (Grativol et al. 2011) and Cicer arietinum (Choudhary et al. 2013), Phoenix dactylifera (Kareem et al. 2018). In this study, a PIC of 0.40 was obtained, higher than the 0.37 value reported by Salazer et al. (2006). The UPGMA cluster analysis and PCoA showed a similar pattern in this study and similar relationship between both analyses have been reported by Ercan et al. (2004) and Salazer et al. (2006).

In conclusion, using as few as ten primers, RAPD marker analysis revealed a high level of genetic diversity among sesame germplasms collected from various geographical zones of West Bengal, India. Finally, it can be surmountable that high level of diversity was obtained by RAPD marker-based analysis and thus this technique can be used for the selection of parents in sesame breeding program.

\section{Acknowledgements}

This research is supported by a Grant from the University Grants Commission, New Delhi, Government of India. The first and second author contributed equally to this manuscript. Authors also gratefully acknowledge the DST-PURSE and Department of Botany, University of Kalyani for Central Instrumental Facilities.

\section{References}

Abdellatef E, Sirelkhatem R, Mohamed Ahmed MM, Radwan KH, Khalafalla MM (2008) Study of genetic diversity in Sudanese sesame (Sesamum indicum L.) germplasm using random amplified polymorphic DNA (RAPD) markers. Afr J Biotechnol 7:4423-4427.

Akbar F, Rabbani MA, Masood MS, Shinwari ZK (2011) Genetic diversity of sesame (Sesamum indicum L.) germplasm from Pakistan using RAPD markers. Pak J Bot 43:2153-2160.

Ali Al-Somain BH, Migdadi HM, Al-Faifi SA (2017) Assessment of genetic diversity of sesame accessions collected from different ecological regions using sequence-related amplified polymorphism markers. 3Biotech 7:82. 
Ashri A (1989) Sesame. In Roebbelen G, Downey RK, Ashri A, Eds., Oil Crop of the World. McGraw Hill, New York, 375-387.

Ashri A (1998) Sesame breeding. Plant Breed Rev 16:179-228.

Bedigian D (2010) Characterization of sesame (Sesamum indicum L.) germplasm: A critique. Genet Resour Crop Evol 57:641-647.

Bedigian D, Seigler DS, Harlan JR (1985) Sesamin, sesamolin and the origin of sesame. Biochem Syst Ecol 13:133-139.

Bhat KV, Babrekar PP, Lakhanpaul S (1999) Study of genetic diversity in Indian and exotic sesame (Sesamum indicum L.) germplasm using random amplified polymorphic DNA (RAPD) markers. Euphytica 110:21-33.

Brar GS, Ahuja KL (1979) Sesame: It's culture, genetics, breeding and biochemistry. In Malik CP, ed., Annu Rev Plant Sci, Kalyani Publishers, New Delhi, India, 245-31.

Cagrgan MI (2006) Selection and morphological characterization of induced determinate mutants in sesame. Field Crops Res 96:19-24.

Choudhary P, Khanna SM, Jain PK, Bharadwaj C, Kumar K, Lakhera PC, Srinivasan R (2013) Molecular characterization of primary gene pool of chickpea based on ISSR markers. Biochem Genet 51:306-322.

Dar AA, Mudigunda S, Mittal PK, Arumugam (2017) Comparative assessment of genetic diversity in Sesamum indicum L. using RAPD and SSR markers. 3Biotech 7:10.

Dixit A, Jin MH, Chung JW (2005) Development of polymorphic microsatellite markers in sesame (Sesamum indicum L.). Mol Ecol Notes 5:736-738.

Doldi ML, Volmann J, Lelley T (1997) Genetic diversity in soybean as determined by RAPD and microsatellite analysis. Plant Breed 116:331-335.

Economic Review-Finance Department, Government of West Bengal (2011-2012) http://www.wbfin.nic.in/ writereaddata/EconomicReview11_Part2.pdf accessed on 20 May 2014.

Ercan AG, Taskin M, Turgut K (2004) Analysis of genetic diversity in Turkish sesame (Sesamum indicum L.) populations using RAPD markers. Genet Resour Crop Evol 51: 599-607.

Ercan AG, Taskin KM, Turgut K, Bilgen M (2002) Characterization of Turkish sesame (Sesamum indicum L.) landraces using agronomic and orphologic descriptors. Akdeniz Univ Ziraat Fak Derg 15:45-52.

FAO (2016) FAOSTAT Database. http://faostat.fao.org/ site/567/DesktopDefault.aspx?PageID=567\#ancor. Accessed on 21 July 2018. http://www.fao.org/faostat/ en/\#data/QC.

Fitzgerald MA, McCouch SR, Hall RD (2009) Not just a grain of rice: the quest for quality. Trends Plant Sci 14:133-139.

Furat S, Uzun B (2010) The use of agro-morphological characters for the assessment of genetic diversity in sesame (Sesamum indicum L.). Plant Omics 3:85-91.
Grativol C, da Fonseca Lira-Medeiros C, Hemerly AS, Ferreira PCG (2011) High efficiency and reliability of intersimple sequence repeats (ISSR) markers for evaluation of genetic diversity in Brazilian cultivated Jatropha curcas L. accessions. Mol Biol Rep 38:4245-4256.

Hamid KA, Ibrahim AS, Taha MB, Ahmed ME (2003) Performance, interrelationship and path analysis of some yield component in sesame. Univ Khartoum J Agric Sci 11:305-320.

Isshiki S, Umezaki T (1997) Genetic variations of isozymes in cultivated sesame (Sesamum indicum L.). Euphytica 93:375-377.

Jaccard P (1908) Nouvelles researches sur la distribution florale. Bull Soc vaud sci natur 44:223-270.

Joshi AB (1961) Monograph of Sesame. First Ed. Published by Indian Central Oilseeds Committee, Hyderabad. Junagadh, Sesamum, 366-434.

Kareem MAH, Al-Saadi AH, Naji HF (2018) Genetic diversity of Iraqi date palm (Phoenix dactylifera L.) by using RAPD technique. JUBPAS 26:114-131.

Kim DH, Zur G, Danin-Poleg Y, Lee SW, Shim KB, Kang CW, Kashi Y (2002) Genetic relationship of sesame germplasm collection as revealed by inter-simple sequence repeats. Plant Breed 121:259-262.

Ko MK, Yang J, Jin YH, Lee CH, Oh BJ (1998) Genetic relationships of Viola species evaluated by random amplified polymorphic DNA analysis. J Hortic Sci Biotech 73:601-605.

Kumar H, Kaura G, Bangaa S (2012) Molecular characterization and assessment of genetic diversity in sesame (Sesamum indicum L.) germplasm collection using ISSR markers. J Crop Improv 26:540-557.

Kumari A, Paul S, Sharma V (2017) Genetic diversity analysis using RAPD and ISSR markers revealed discrete genetic makeup in relation to fibre and oil content in Linum usitatissimum L. genotypes. Nucleus 61:45-53.

Li M, Midmore DJ (1999) Estimating the genetic relationships of Chinese water chestnut (Eleocharis dulcis (Burm. f.) Hensch.) cultivated in Australia, using random amplified polymorphic DNAs (RAPDs). J Hortic Sci Biotechnol 74:224-231.

Laurentin HE, Karlovsky P (2006) Genetic relationship and diversity in a sesame (Sesamum indicum L.) germplasm collection using amplified fragment length polymorphism (AFLP). BMC Genetics 7:1-10.

Lowe A, Harris S, Ashton P (2004) Ecological Genetics: Design Analysis and Application. Blackwell, Oxford.

Malviya N, Sarangi BK, Yadav MK, Yadav D (2012) Analysis of genetic diversity in cowpea (Vigna unguiculata L.Walp) cultivars with random amplified polymorphic DNA markers. Plant Syst Evol 298:523-526.

Mazanni B (1983) Ajonjoli. In Cultivo y Majoramiento de Plant as Oleaginosas. FONAIP. Caracas, Venezuela. 
$162-224$.

Millan T, Osuna F, Cobos S, Torres AM, Cubero JI (1996) Using RAPDs to study phylogenetic relationships in Rosa. Theor Appl Genet 92:273-277.

Murray HG, Thompson WF (1980) Rapid isolation of high molecular weight DNA. Nucleic Acids Res 8:4321-4325.

Naik PK, Alam MF, Singh H, Goyal V, Parida S, Kalia S, Mohapatra T (2010) Assessment of genetic diversity through RAPD, ISSR and AFLP markers in Podophyllum hexandrum: A medicinal herb from the Northwestern Himalayan region. Physiol Mol Biol Plants 16:135-148.

Nei M (1973) Analysis of gene diversity in subdivided populations. Proc Natl Acad Sci USA 70:3321-3323.

Orhan E, Ercisli S, Yildirim N, Agar G (2007) Genetic variation among mulberry genotypes (Morus alba) as revealed by Randomly Amplified Polymorphic DNA (RAPD) markers. Plant Syst Evol 265:251-258.

Pandey SK, Das A, Rai P, Dasgupta T (2015) Morphological and genetic diversity assessment of sesame (Sesamum indicum L.) accessions differing in origin. Physiol Mol Biol Plants 21:519-529.

Pham TD, Bui TM, Werlemark G, Bui TC, Merker A, Carlsson AS (2009) A study of genetic diversity of sesame (Sesamum indicum L.) in Vietnam and Cambodia estimated by RAPD markers. Genet Resour Crop Evol 56:679-690.

Pham TD, Nguyen TDT, Carlsson AS, Bui TM (2010) Morphological evaluation of sesame (Sesamum indicum L.) varieties from different origins. Austral J Crop Sci 4:498-504.

Powell W, Morgante M, Andre C, Hanafey M, Vogel J, Tingey S, Rafalski A (1996) The comparison of RFLP, RAPD, AFLP and ISSR and SSR (microsatellite) markers for germplasm analysis. Mol Breed 2:225-238.

Prevost A, Wilkinson MJ (1999) A new system of comparing PCR primers applied to ISSR fingerprinting of potato cultivars. Theor Appl Genet 98:107-112.

Quenum F, Yan Q (2017) Assessing genetic variation and relationships among a mini core germplasm of sesame (Sesamum indicum L.) using biochemical and RAPD markers. Am J Plant Sci 8:311-327.

Russell JR, Fuller JD, Macaulay M, Hatz BG, Jahoor A, Powell W, Waugh R (1997) Direct comparison of levels of genetic variation among barley accessions detected by RFLPs, AFLPs, SSRs a RAPDs. Theor Appl Genet 95:714-722.

Rohlf FJ (1993) NTSYS-pc. Numerical Taxonomy and Multivariate Analysis System. version 2.11. Applied Biostatistics. Exeter Software, Setauket, New York.

Roldán-Ruiz I, Dendauw J, Van Bockstaele E, Depicker A, De Loose M (2000) AFLP markers reveal high polymorphic rates in ryegrasses (Lolium spp.). Mol Breed 6:125-134.

Salazar B, Laurentin H, Davila M, Castillo MA (2006) Reliability of the RAPD technique for germplasm analysis of sesame (Sesamum indicum L.) from Venezuela. Interciencia
J 31:456-460.

Sangwan NS, Jadav U, Sangwan RS (2001) Molecular analysis of genetic diversity in elite Indian cultivars of essential oil trade types of aromatic grasses (Cymbopogon species). Plant Cell Rep 20:437-444.

Schontz D, Rether B (1999) Genetic variability in foxtail millet, Setaria italic (L.) P. Beauv.: Identification and classification of limes with RAPD markers. Plant Breed 118:190-192.

Shannon C, Weaver W (1949) The Mathematical Theory of Communication. University of Illinois Press, Urbana, USA.

Sharma SN, Kumar V, Mathur S (2009) Comparative analysis of RAPD and ISSR markers for characterization of sesame (Sesamum indicum L.) genotypes. J Plant Biochem Biotechnol 18:37-43.

Singh P, Singh SP, Tiwari AK, Sharma BL (2017) Genetic diversity of sugarcane hybrid cultivars by RAPD markers. 3Biotech 7:222.

Slatin M (1987) Gene flow and geographic structure of natural populations. Science 236:787-792.

Stankiewicz M, Gadamski G, Gawronski SW (2001) Genetic variation and phylogenetic relationships of triazine-resistant and triazine-susceptible biotypes of Solanum nigrum - analysis using RAPD markers. Weed Res 41:287-300.

Woldesenbet DT, Tesfaye K, Bekele E (2015) Genetic diversity of sesame germplasm collection (Sesamum indicum L.): implication for conservation, improvement and use. Int J Biotechnol Mol Biol Res 6:7-18.

Uzun B, Lee D, Donini P (2003) Identification of a molecular marker linked to the closed capsule mutant trait in sesame using AFLP. Plant Breed 122:95-97.

Varshney RK, Chabane K, Hendre PS, Aggarwal RK, Graner A (2007) Comparative assessment of EST-SSR, EST-SNP and AFLP markers for evaluation of genetic diversity and conservation of genetic resources using wild, cultivated and elite barleys. Plant Sci 173:638-649.

Vieira RF, Goldsbrough PB, Simon JE (2003) Genetic diversity of basil based on RAPD markers. J Am Soc Hortic Sci 128:94-99.

Williams JG, Kubelik AR, Livak KJ, Rafalski JA, Tingey SV (1990) DNA polymorphisms amplified by arbitrary primers are useful as genetic markers. Nucleic Acids Res 18:6531-6535.

Yeh FC, Yang R, Boyle T (1999) PopGene: Microsoft Windows-based freeware for population genetical analysis, version 3.2. University of Alberta, Edmonton.

Yermanos DM (1980) Sesame. In Fehr WR and Hadley HH, eds., Hybridization of Crop Plants. Am Soc Agron, CSSA, Madison, Wisconsin, USA. 549-563.

Zhang H, Wei L, Miao H, Zhang T, Wang C (2012) Development and validation of genetic-SSR markers in sesame by RNA-seq. BMC Genomics 13:316 